\title{
Authors' reply to: Prophylactic mesh to prevent parastomal hernia: a meta-analysis of randomized controlled studies (Tech Coloproctol (2017) 21:5-13)
}

\author{
S. D. Wexner ${ }^{1}$
}

Received: 14 May 2017/ Accepted: 15 May 2017/Published online: 15 June 2017

(c) Springer International Publishing AG 2017

I thank the authors of the letters about the recently published meta-analysis on parastomal hernia [1] including Mr. Stephenson who spent time with us at Cleveland Clinic Florida. To first address the valid points raised by $\mathrm{Mr}$. Stephenson and his colleagues, I concur $100 \%$ with their question "why is mesh prophylaxis now not routine?" However, our answer is somewhat different from theirs. I think that cost considerations throughout the health care system in North America and possibly elsewhere sadly often preclude or delay the introduction of new technology. Hopefully, one of the advantages of the publication of multiple new randomized controlled trials and multiple meta-analyses is that is that both payors and healthcare systems may be more inclined to allow more timely inclusion of new technology. I agree with the statement made by Mr. Nepogodiev and coworkers that the international prospective registry of systematic reviews seems a very useful instrument. However, the ability of different sets of authors to comment, interpret, and discuss data will hopefully allow technology which is by those very publications "proven" to improve outcomes to be more readily and rapidly introduced into clinical practice. Both randomized controlled trials and meta-analyses are potentially useful instruments in our continual quest to improve outcomes for our patients. Unfortunately, our current healthcare systems often impose an intermediary decision maker between the surgeon and the patient in the form of a governor or regulator of technologic introduction, the payor. I thank the authors for their insightful comments.

\section{Compliance with ethical standards}

Conflict of interest The author declares that he has no relevant financial conflict of interest.

Ethical approval This article does not contain any studies with human participants or animals performed by the author.

Informed consent For this type of study formal consent is not required.

\section{Reference}

1. Patel SV, Zhang L, Chadi S, Wexner SD (2017) Prophylactic mesh to prevent parastomal hernia: a meta-analysis of randomized controlled studies. Tech Coloproctol 21:5-13

\footnotetext{
S. D. Wexner

wexners@ccf.org

1 Cleveland Clinic Florida, Weston, FL, USA
} 